\title{
Crianças nos templos das Musas: mediadores culturais, processos de significação e aprendizagens em museus
}

\author{
Children in the temples of the Muses: cultural \\ mediators, meaning processes and learning in museums
}

Maria Fernanda van Erven*

Sonia Regina Miranda ${ }^{* *}$

Resumo

O objetivo deste artigo é oferecer ao leitor - especialmente aos educadores que atuam em instituições museais e/ou em escolas que buscam explorar o potencial pedagógico existente nos espaços educativos da cidade - reflexões derivadas de uma investigação desenvolvida entre os anos de 2011 e 2013 junto ao Programa de PósGraduação em Educação da Universidade Federal de Juiz de Fora. Aquela pesquisa dedicou-se a compreender as aprendizagens que se processam em museus buscando qualificar em que medida as instituições museais podem funcionar como espaços potentes no sentido de engendrar práticas pedagógicas múltiplas e criadoras na sala de aula. Por isso pensamos na ambígua relação que se pode focalizar envolvendo crianças se relacionando com o Tempo no interior dos novos Templos das Musas. Priorizou-se a compreensão sobre os processos de significação produzidos

\section{Abstract}

The aim of this article is offer to the reader - specially to educators what act in museum institutions or in schools that seek to exploit the pedagogical potential existing on educational places of city derived reflections of one developed investigation between the years 2011 and 2013 by the Post Graduate Program in Education of Universidade Federal de Juiz de Fora. That research dedicated to understanding the learning in process museums seeking qualifying the extent to museum institutions like potent places in order to engender multiply pedagogical practices and creative inside the classrooms. So we think of the ambiguous relation that can focus on involving children in relationship to the time within the new Muses Temples. Prioritized the understanding about the signification processes produced by children within of Museums, starting from gamble in idea

\footnotetext{
${ }^{\star}$ Graduada em História, Mestre em Educação, Universidade Federal de Juiz de Fora (UFJF). mariavanerven@gmail.com

**Doutora em Educação, Professora da Universidade Federal de Juiz de Fora (UFJF).sonia.miranda@ ufjf.edu.br
} 
por crianças no interior de museus, partindo-se da aposta política na ideia de que, enquanto espaços educadores presentes e/ ou possíveis de existir nas cidades, o direito à cidade representa também o direito à cultura da/na cidade e, acima de tudo, o direito à memória.

Palavras-chave: ensino de História; educação em museus; aprendizagens históricas; práticas sociais de memória. policies that as educators places present and / or possible to exist in the cities, the right to the city is also the right of the culture of / in the city and, above of all, the memory right.

Keywords: History teaching; museum education; historical learning; social practices of memory.

El museo, el museo... ¿ qué es eso? ¿Templo de las musas o palacio de las musarañas? ¿Lugar de plasmación objetual del espíritu humano o deshumanización espiritual de objetos antes dotados de funcionalidad? ¿Guardería - camuflada - para escolares y otros aprendices más crecidos? ¿Centro de atracciones - estáticas - y actividades multimedia? ¿Escala obligada para quien se precie de estar al día en cuanto a rituales de consumo cultural? ¿Tienda solapada donde se venden libros - con santos preciosos - perfectos para colocar en la estantería de la sala de estar? ¿Para qué sirve el museo? ¿A qué vamos al museo, si vamos? ¿Québuscamos allí? ¿Resguardarnos de la lluvia? ¿Cumplir con el programa de visita turística? ¿Matar el tiempo cuando no se nos ocurre nada mejor de hacer? ¿Ampliar nuestros conocimientos? ¿Donde, en una pared con textos incomprensibles? ¿En las hojas y folletos explicativos que casi siempre están agotados o no coinciden con la sala en la que nos encontramos? A quién preguntamos en caso de duda?

Ignácio Balerdi

\section{MUSEUS: ESPAÇOS PARA APRENDER?}

As perguntas que aqui evocamos como epígrafe estão presentes no início da obra de Ignácio Balerdi (2008) e seguem por dezenas de outras questões, provocativas e provocadoras de pensamento, tanto por sua ironia como por sua complexidade, por mais de duas páginas no convite à reflexão. Ele mesmo - ao final de tantas perguntas lançadas freneticamente ao leitor, como numa tempestade mental - nos alerta para o fato de que não tentará, naquela obra, responder a todas porque cada uma delas, por certo, funcionaria como uma 
porta aberta para tantas novas questões. Todavia, o vasto conjunto de perguntas, complexas, desconfiadas e até mesmo curiosas, serve para nos convocar a refletir sobre o quão importante é investigar o que acontece com os sujeitos quando se vai a um museu. Que aprendizagens são ali processadas? Aprende-se mesmo no interior de um museu? Como? Por meio de quais mecanismos? Quais suas singularidades em face das aprendizagens que se operam no espaço escolar? Crianças e adultos aprendem do mesmo modo no interior desse espaço? Todas essas perguntas nos conduzem a pensar na força e na potencialidade investigativa que se dispõe quando paramos para refletir sobre esses Templos que nos conduzem a olhar o Tempo.

Os museus, em todo o mundo, têm crescido e se destacado, ao longo das últimas décadas, como novas modalidades de espaços educativos. Isso representa dizer que a compreensão relativa às suas dinâmicas, linguagens e possibilidades pedagógicas tem aberto não só novos campos de atuação profissional para educadores e historiadores, como também o campo investigativo do ensino de História. Por decorrência desse novo desenho de nosso mercado profissional, temos assistido a uma considerável expansão dos estudos que priorizam o entendimento do que representa aprender o tempo, as relações sociais e o conhecimento histórico a partir daquilo que se dispõe para os visitantes nos espaços museais. Atividades direcionadas para o público, junto às ações educativas ancoradas na busca de parâmetros interpretativos e teóricos acerca dos processos educativos e enunciativos, vêm ganhando, em todo o mundo, cada vez mais espaço e importância dentro e fora dos museus.

Cada vez mais vemos museus produzindo materiais, prestando serviços, influindo no debate acerca de políticas públicas para a Educação e Cultura e contratando profissionais para cumprir esse vasto rol de tarefas. A sua significativa ampliação numérica e quantitativa, como espaços de cultura nas cidades, vem ampliando, também, a possibilidade de parcerias com as escolas.

No cenário internacional é vasto o domínio de trabalhos que se dedicam a qualificar esse novo campo, investigando questões que vão desde a dimensão da expografia e as decisões de linguagem que afetam a materialidade dos museus até trabalhos que tentam dar conta da interpretação estética, ética e política daquilo que se processa nesses espaços. Ignácio Balerdi (2008), por exemplo, faz-nos refletir sobre o fato de que na medida em que os museus devolvem ao público, em tempos distintos, o que fora outrora privatizado, suas 
possibilidades abertas de releitura por parte do público e de seus agentes fazem que esses espaços tenham sempre em si um embrião no qual a potência de conservação é permanentemente tensionada diante da potência iminente de transformação de seus pressupostos ao longo do tempo. Roser Calaf (2009), por sua vez, nos convida a refletir sobre marcos teóricos e epistemológicos que nos permitam avançar na elaboração de uma didática para o patrimônio. Essa mesma busca 'didática' conduz autores como Joan Santacana $(2009 ; 2012)$ e Francesc Xavier Hernández $(2006 ; 2009 ; 2012)$ à elaboração de projetos didáticos e de museografia que, por vezes, avançam na produção de espaços e produtos ficcionais por diversas regiões e museus europeus, por exemplo, nos quais o passado é reinventado e criado à luz de suportes de linguagem permeados por um realismo que visa criar cenários sensoriais capazes de "conectar" os sujeitos visitantes com aquilo que teria ocorrido no passado. Sem dúvida, um modo de proposição que chama públicos e produz novas mercadorias, conectadas a um mundo ancorado em informações rápidas e permeadas pela virtualidade.

Os diálogos e potencialidades educativas envolvendo as relações possíveis de serem estabelecidas entre museus e escolas tem sido, entretanto, especialmente na América Latina, um espaço histórico no qual o tema da Memória tem se constituído, graças ao compartilhamento de uma experiência social de ditaduras que produzem muitos silenciamentos e apagamentos. Assim, não só o tema da Memória vem ganhando grande expansão, como também os espaços dedicados à produção/custódia de Memórias têm sido perseguidos em trilhas investigativas diversas, tais como, por exemplo, aquelas construídas e difundidas por meio dos trabalhos de Silvia Aderoqui (2006; 2011). O que queremos ressaltar com isso é que o tema da Educação em Museus só cresce, tanto na materialidade das instituições, como na ação investigativa que congrega cada vez mais pesquisadores no Brasil e no mundo. Isso significa dizer que o tema da Educação em Museus, para além de sua transdisciplinaridade, tem se projetado como um fortíssimo tema atinente ao campo investigativo do ensino de História.

Isso significa dizer que, se por um lado, museus podem e tendem, muitas vezes, a se manter como instituições dedicadas à preservação e cristalização de um dado projeto de Memória, por outro lado sempre um novo uso de seu acervo pode redimensionar aquele projeto de Memória outrora concebido, 
gerando contínuas possibilidades de releitura. Nessa direção, Ignácio Balerdi nos convida a pensar no fato de que sempre o museu traz em si a possibilidade de deslocamento de uma propriedade individual à propriedade coletiva e pública; sempre conviverá com a possibilidade de deslocar um acesso como privilégio para acesso enquanto direito; sempre poderá substituir os caprichos do colecionista por critérios e leituras de curadores e especialistas dedicados à tarefa de didatização e comunicação de uma dada coleção; sempre poderá ensejar a visibilidade em substituição à sua desordem iminente, criada em virtude da natureza e movimento das coleções. Acima de tudo, segundo aquele autor, sempre museus trarão em si a potência embrionária da trindade conceitual: percurso, orientação e ordem que toma o corpo que se desloca a partir de uma autêntica pedagogia do olhar.

No caso brasileiro, autores como Francisco Regis Ramos, Mario Chagas, Júnia Sales Pereira e Lana Mara Siman, dentre muitos outros pesquisadores, têm oferecido contribuições importantes para qualificar o campo da Educação em Museus com base naquilo que se torna essencial: refletir sobre os museus enquanto espaços que educam a partir de condicionantes de linguagem e práticas pedagógicas que lhe são próprios, sem perder de vista aquilo que vem constituindo o grande alerta proposto por Mário Chagas (2006): “os museus vinculados às musas por via materna são 'lugares de memória’ (Mnemósine é mãe das musas); mas por via paterna estão vinculados a Zeus, são estruturas e lugares de poder. Assim, os museus são a um só tempo: lugares de memória e de poder. Estes dois conceitos estão permanentemente articulados em toda e qualquer instituição museológica". Se considerarmos essa "paternidade" de Zeus e refletirmos sobre como os novos e grandes projetos museais emergentes no Brasil vinculam-se espacialmente aos projetos de gentrificação das cidades, para nos basearmos nos movimentos interpretativos trazidos pela reflexão de Rogério Proença Leite, nos daremos conta de que cada vez mais os novos museus depararão com velhos problemas. Por um lado, novos museus e espaços culturais tendem a representar a expansão da oferta de bens culturais à população, ainda que situados em meio a enclousures derivados da modernização urbana ancorada nas demandas do grande capital. O que vemos acontecer hoje na cidade do Rio de Janeiro, por exemplo, é emblemático desse tipo de contradição, na qual a modernização de uma área degradada da cidade, como a região do antigo Porto, vem seguida de novos e emblemáticos projetos museais que, 
todavia, não dialogam com o conjunto da cidade e ancoram-se em um dado projeto de memória. Por outro lado, tais instituições museais passam a conviver cotidianamente com os muitos dilemas derivados da necessária criação de mecanismos que permitam aos diferentes sujeitos se compreenderem como pertencentes e socialmente incluídos nesses novos espaços públicos.

\section{SObRe AS MUITAS CIDAdES ENTRE OS MUSEUS DA CIDADE:} SOBRE A EDUCAÇÃO MUSEAL COMO PRÁTICA CIDADÃ

Em certa medida, se considerarmos que também os currículos escolares podem ser vistos como lugares de memória e poder - para o que a metáfora de Zeus versus Mnemósine segue válida - continuamente atravessados, portanto, pelo componente da sua renovação temporal, parece-nos relevante refletir acerca dos modos pelos quais essas duas instituições - escola e museu - se cruzam em sua potência educadora e provocadora do pensamento e do saber, quando colocadas em relação pela prática escolar.

Tendo em vista esses marcos conceituais aqui citados, partimos de uma pergunta central que norteou toda a investigação, desenvolvida com crianças que tiveram a oportunidade de visitar - na maior parte dos casos pela primeira vez em suas vidas - duas das mais importantes instituições museais da cidade de Juiz de Fora: o Museu de Arte Murilo Mendes (MAMM) e o Museu Ferroviário. ${ }^{1}$ Daí já decorre um aspecto central inerente ao trabalho educativo com museus: a construção do Direito das crianças e jovens em conhecer sua própria cidade.

Interessava-nos responder a uma grande pergunta: como se dá a relação do sujeito visitante com o museu e com os objetos musealizados? Colocando de outro modo, o que acontece quando uma criança entra num espaço museal? Quais são as reações das crianças? Com que ferramentas de olhar e modos de leitura a criança percorre esse espaço? Que comportamentos e emoções são disparados pelos museus na criança que tem a chance de conhecê-los e apropriar-se deles? O que nasce dessa relação? Que sentidos educativos são disparados nesse movimento de leitura de objetos e ambientes?

A pesquisa dialogou com crianças do $5^{\circ}$ ano do Ensino Fundamental da Escola Municipal José Calil Ahouagi, situada na periferia da cidade de Juiz de Fora e que, historicamente, atende a público formado por sujeitos migrantes 
no interior da própria cidade, isto é, filhos de caseiros, empregados de granjas de alto luxo mas que frequentemente se encontram em situações de instabilidade diante do risco iminente de desemprego e da alta rotatividade das famílias nesses postos de trabalho. Ao mesmo tempo, sujeitos que, residentes numa dada região da cidade, desconhecem, em sua grande maioria, a cidade em sua totalidade, ou ao menos em relação à sua área central. Interessava-nos focalizar os significados possíveis de serem depreendidos do fato de que a visita a museus, por parte de crianças que residem na periferia, pode estabelecer outros fluxos e circuitos de relação com a cidade, que àquelas crianças lhes soa tão familiar e, ao mesmo tempo, tão estranha e distante.

Para além desse fato, a escolha dessa escola se deveu ao fato de ser ela uma instituição acostumada à prática da pesquisa acadêmica no interior de seus muros, práticas e corredores, que se transforma continuamente e se nutre pedagogicamente dessa prática. Uma escola onde já foram gestadas e desenvolvidas várias dissertações de Mestrado e teses de Doutorado, todas elas sempre vinculadas a possibilidades de reconstrução de trajetos e práticas pedagógicas por parte da própria escola, considerando-se aquilo que era apontado pelas diversas investigações.

A pesquisa de campo se constituiu em torno de três grandes momentos. O primeiro foi marcado pela visita ao Museu de Arte Murilo Mendes (MAMM), um museu de arte contemporânea, vinculado à Universidade Federal de Juiz de Fora (UFJF) e que organiza boa parte de sua agenda em torno de exposições temporárias. O acervo do MAMM é composto por obras de artistas brasileiros e estrangeiros, entre eles James Ensor, Giorgio De Chirico, Max Ernst, Picasso, Braque, Miró, Ismael Nery, Portinari, Líder, Ar, Vieira da Silva, Jesus Rafael Soto e Guignard (Almeida, 2007). As obras pertenciam à coleção de artes plásticas de Murilo Mendes que, após vários anos de negociação e o atendimento das exigências solicitadas, vieram para o Brasil. Segundo Almeida (2007), foi com a vinda dessas obras para o Brasil que se inaugurou, oficialmente, o Centro de Estudos Murilo Mendes (CEMM). O CEMM finalizou suas atividades em 2005, ano em que foi inaugurado o MAM (Museu de Arte Moderna) que, posteriormente, passou a se chamar Museu de Arte Murilo Mendes. Antes da vinda do acervo de artes plásticas para o Brasil, Maria da Saudade (viúva de Murilo Mendes) doou a biblioteca particular do escritor (composta por 2.800 volumes) à UFJF. Dessa forma, hoje o MAMM é 
composto por quatro bibliotecas, laboratórios de conservação e restauração (um de papel e o outro de artes plásticas) e três espaços expositivos (galerias Retratos Relâmpago, Poliedro e Convergência). As exposições visitadas pelas crianças, nesta pesquisa, em novembro de 2012, foram: "Santos Todos Nós", de Hélio Siqueira, e "Pinturas na coleção Murilo Mendes", agora já encerradas.

Trata-se de um museu situado no centro da cidade, no espaço que durante anos foi ocupado pela Reitoria da UFJF, e que vivencia o desafio cotidiano de fazer-se frequentado e apropriado efetivamente pelo público da cidade, que ainda o considera como um espaço público distante, excludente e apartado da convivência cidadã.

$\mathrm{O}$ segundo momento da pesquisa foi marcado pela visita ao Museu Ferroviário, espaço situado em um dos marcos da Belle Époque mineira, em uma praça onde se localizava, já no século XIX, a estação de trem da cidade e, nesse sentido, espaço dotado de uma longevidade temporal ampliada e grande densidade cultural e social no que tange ao tecido urbano, uma vez que se trata de espaço para o qual confluem as principais linhas de ônibus que ligam o centro da cidade a todos os bairros da periferia urbana. Um museu situado, portanto, em um dos mais importantes espaços de passagem e de acesso popular da cidade. Além disso, organizado enquanto museu temático e com uma categorização específica - um museu "histórico" -, o acervo ali presente remete o visitante a aspectos de um modo específico de compreender o tempo em sua relação com o passado. Localizado na sede da antiga Estrada de Ferro Leopoldina, seu prédio faz parte do conjunto arquitetônico da Praça da Estação (Praça Doutor João Penido), que agrega grande número de prédios históricos ao seu redor. Sua inauguração ocorreu em agosto de 2003. Até essa data, o edifício passou por uma série de transformações que abarcaram a revitalização, a reestruturação e a modernização/atualização daquele ambiente. A constituição, montagem e pesquisa da exposição remontam a essa época. A exposição é permanente e não sofreu alterações, até hoje. A única exceção é a maquete que localiza o edifício do museu no centro da cidade de Juiz de Fora e faz parte da exposição desde 2011. O acervo é composto por cerca de quatrocentos objetos cujo objetivo é contar a história da ferrovia, ou seja, mostrar a sua origem e também as suas transformações no decorrer do tempo. Essa história é contada de forma linear. 
O terceiro momento da pesquisa envolveu o acompanhamento do trabalho desenvolvido pela professora de História na sala de aula, junto às crianças, o que chamamos de pós-visita e que correspondeu aos aspectos de maior surpresa no tocante à pesquisa.

As intencionalidades e os pressupostos adotados por cada museu nem sempre são claros e óbvios, mas são sempre reveladores de culturas históricas hegemônicas. Segundo Miranda (2010), “a linguagem museográfica não é neutra e o discurso dela derivado é também um discurso produtor de memórias e de sentidos identitários" (p.375). Nesse sentido, os discursos assumidos por cada instituição revelam uma determinada forma de se compreender o papel que aquele museu assume com a sociedade, em especial, com seus sujeitos visitantes.

Nos dois casos evocados em nossa pesquisa, podemos apontar, por um lado, no Museu de Arte Murilo Mendes o quanto potencializa-se aquilo que Ulpiano Bezerra de Meneses (2010) destaca como a fruição estética e percepção sensorial que se projeta como um dos usos prioritários que podem ser assumidos por um museu, aspecto constantemente renovado em virtude da rotatividade imposta pelas exposições temporárias. No caso das duas exposições visitadas com as crianças participantes da pesquisa, podemos depreender que na série "Santos todos Nós" de Hélio Siqueira, o artista "dessacraliza o status dos santos, humanizando-os como homens comuns, todos numa grande procissão de desvalidos e abandonados no vaivém dos tempos. A atualidade do trabalho está nisso: o homem à deriva na imensidão deste oceano/mundo" (Siqueira, 2000, p.34).

Já a exposição "Pinturas na coleção de Murilo Mendes" trazia todas as pinturas do acervo de Murilo Mendes, expostas juntas pela primeira vez.

As técnicas presentes na exposição misturam-se entre guache, óleo, acrílica e têmpera, em sua maioria marcadas pela textura e pela visualidade, como acontece na poesia de Murilo, que apresenta frases quase físicas, que ocupam concretamente seu espaço no papel. ${ }^{2}$

A maior parte dos quadros expostos na Galeria Convergência era de pintores europeus, produzidos quando Murilo Mendes morou em Roma, na Itália. Entre eles, havia duas obras de Alberto Magnelli dedicadas ao poeta brasileiro. Havia obras de Arpad Szenes (um óleo) e Maria Helena Vieira da Silva (quatro 
guaches), e também dos italianos Gastone Biggi, Piero Dorazio, Michaelangelo Conte, Mario Marianni, Mário Padovan e Achille Perilli.

De acordo com o próprio museu, a mostra "Pinturas na coleção Murilo Mendes" foi montada para "provocar o visitante a recriar os quadros expostos, levando o espectador a repensar seus próprios valores sobre a arte e a pintura". ${ }^{3}$

Já no Museu Ferroviário, ainda que não desprovido da dimensão da fruição estética pulsante no Museu de Arte, a perspectiva linear e factual, ancorada numa proposta pedagógica voltada à aquisição informativa, se impõe ao visitante. Grandes personagens históricos e fatos relevantes surgem como elementos centrais desse passado. Sua expografia se centra mais na descrição do passado do que propriamente na problematização do presente. O ponto de partida narrativo ancora-se em uma perspectiva genético-evolutiva e é o passado que se organiza como referente para se chegar ao presente, ou pelo menos próximo a ele. Torna-se desafiador para o professor - e, portanto, abre-se como uma janela suscetível à prática pedagógica em sala de aula - explicar as continuidades, descontinuidades, mudanças e transformações, diante de tal perspectiva.

$\mathrm{O}$ fato de aquele museu falar do passado, de um lugar onde o movimento do trem pela estação realmente ocorreu, concede a esse espaço uma aura de veracidade. É como se pudéssemos voltar ao passado e observar como tudo teria supostamente acontecido, uma vez que os objetos ali presentes representariam a confirmação de que tal passado existiu. Esse atestado de veracidade e esse "retorno" ao passado possuem duas facetas importantes para a reflexão sobre práticas pedagógicas, tanto no museu quanto na escola. Torna-se um grande atrativo para o público, mas há a necessidade de se problematizar, permanentemente, tal perspectiva, sob o risco de não se constituir uma relação com o saber e com o conhecimento a partir de uma atividade intelectual ativa. No caso da aprendizagem da História, é necessária a compreensão de que o passado não pode ser trazido à tona tal qual ele foi, mas é possível revisitá-lo permanentemente a partir das fontes, objetos, práticas, hábitos e ideias, entre outros, o que nos conduz à formação, junto ao estudante, de uma atitude compreensiva diante da provisoriedade explicativa.

O fio do progresso foi eleito, pelo Museu Ferroviário, como um eixo narrativo central. Sua expografia procurou, portanto, vincular a história de Juiz de Fora ao desenvolvimento e progresso da ferrovia. Nessa perspectiva, 
assumida pelo museu, falar sobre a história da ferrovia em Juiz de Fora é, de certa maneira, falar da própria origem e desenvolvimento da cidade. Esse gancho é, visivelmente, utilizado dentro do Museu Ferroviário. A todo tempo se busca essa relação.

Os objetos estão dispostos de modo a recriar ambientes (cenários) e também de forma didática, visando facilitar o entendimento daqueles que visitam o museu, uma vez que grande parte de seu público é escolar. Os painéis, os textos, as maquetes, o ferrorama e as réplicas de locomotivas são exemplos dessa preocupação didática. As peças presentes no museu são: de mobiliário, instrumentos de trabalho e de comunicação, fotografias, equipamentos científicos e técnicos, louças e miniaturas. Estão distribuídas em cinco salas temáticas, a saber: História da Ferrovia, Agência de Estação, Sinalização e Via Permanente, Escritórios Ferroviários e Material Rodante e Aspectos Tecnológicos. Há, também, na parte externa, duas locomotivas a vapor.

Diante da disposição das salas, tornam-se visíveis dois pontos. O primeiro é relativo à ausência de problematização sobre o enfraquecimento e a crise da ferrovia no Brasil. Onde está apresentada a atual situação de abandono da ferrovia em nosso país? O segundo se refere à não apresentação e à consequente negação dos usuários e viventes da ferrovia. Onde estão esses sujeitos e suas narrativas? A decisão do que entra ou não na exposição é uma escolha técnica e política do museu e se reflete diretamente na forma como os sujeitos visitantes se relacionam com o museu, com seus objetos e com o conhecimento gerado.

$\mathrm{O}$ fato central é que nos dois museus o acesso pressupõe o estabelecimento de trânsitos pela cidade, muitas vezes inacessíveis a crianças e jovens a não ser pela intermediação da escola. Mais do que isso, o acesso a diferentes museus ou espaços culturais existentes na cidade permite também o contato com diferentes discursos relativos a projetos de cidade. Trata-se, portanto, do direito à memória interpelando o direito à cidade.

\section{COMO REALIZAR UMA PESQUISA COM CRIANÇAS?}

A investigação que serve de base a este artigo buscou interpretar como crianças se relacionam com o espaço museal, o que é muito distinto de investigar o público adulto interagindo com o museu. Tendo em vista a especificidade desse público, parece-nos relevante indicar de que modo estamos 
compreendendo, metodologicamente, o ato de investigar a criança ou fazer pesquisa com crianças, respeitando seu protagonismo e sua autoria.

Fazer pesquisa com crianças não equivale a investigar crianças e suas reações em relação a um dado conteúdo. Neste último sentido, talvez fosse suficiente, em termos metodológicos num dado formato em termos de script acadêmico, informarmos que a alternativa utilizada foi abordagem qualitativa de inspiração etnográfica. Todavia, parece-nos importante ir além do formalismo, muito recorrente no campo da pesquisa em Educação, e refletir melhor sobre o que significa pesquisar com os sujeitos. Essa escolha é fruto do entendimento da difícil tarefa que é apreender a problemática de pesquisa em questão, já que estamos lidando com fenômenos sociais, na dimensão da cultura e do vivido, o que traz incontáveis repercussões para o desenho da investigação, uma vez que, na maioria das vezes, não se lida com o previsível e controlável, mas com o imprevisível e com o que pode modificar o escopo ordenado a priori para a pesquisa. Como afirmam Silva et al. (2005), para Bakhtin "pesquisa em ciências humanas é sempre estudo de textos: diários de campo, transcrições de entrevistas são, mais do que aparatos técnicos, modos de conhecimento" (p.45). Isso significa dizer que fotografias, observações, notas de campo, entrevistas e cartas produzidas no processo representam sempre dispositivos que produzem narrativas abertas à interpretação. Para tanto, o exercício de um olhar exotópico, conforme a perspectiva bakhtiniana, faz-se essencial.

Primeiramente torna-se central, sob tal perspectiva, o árido exercício de colocar-se no lugar das crianças, tanto no sentido de ver o mundo com os olhos de criança, isto é, "como se estivesse vendo tudo pela primeira vez" (Matisse, 1983, citado em Silva et al. 2005, p.52), quanto de "ver axiologicamente o mundo de dentro dele tal qual ele o vê" (Bakhtin, 2003, p.23).

O retorno para o lugar de pesquisador após o exercício de colocar-se no lugar do outro e conseguir compreender suas lógicas, gestos, atitudes, incompreensões, estranhamentos e insights pressupõe buscar o amparo dos referenciais teóricos selecionados sem que se busque, necessariamente, o enquadramento das descobertas de campo no interior de tais referenciais, num exercício de encaixe vulgar.

O arcabouço criado por Bakhtin tem por base a teoria enunciativa da linguagem que representa, dentro da perspectiva histórico-cultural, uma possibilidade de abordagem. Assim, é por meio do arcabouço conceitual desse 
autor que as crianças no museu foram observadas. A relação que as crianças estabelecem com os objetos no museu está ligada diretamente com a linguagem, pois, para Bakhtin (2003), "todos os campos da atividade humana estão ligados ao uso da linguagem" (p.261). Podemos transpor as assertivas desse teórico para refletirmos sobre as reações disparadas por um objeto musealizado e também pela relação estabelecida com as linguagens presentes no museu.

Foi necessário um olhar atento e uma escuta sensível para que se pudesse compreender os ditos e os não ditos pelas crianças, ou seja, não só suas palavras, mas também seus gestos, olhares e sorrisos.

Por se constituir como um campo das ciências humanas e sociais, na pesquisa com crianças, pesquisamos sempre relações (Vygotsky, 1984), o que torna fundamental ver e ouvir. Ver: observar, construir o olhar, captar e procurar entender, reeducar o olho e a técnica. Ouvir: captar e procurar entender, escutar o que foi dito e o não dito, valorizar a narrativa, entender a história. Ver e ouvir são cruciais para que se possa compreender gestos, discursos e ações. Este aprender de novo a ver e ouvir (a estar lá e estar afastado; participar e anotar; a interagir enquanto observa a interação) se alicerça na sensibilidade e na teoria e é produzido na investigação, mas é também um exercício que se enraíza na trajetória vivida no cotidiano (Silva et al., 2005, p.48).

Tal fato implica o reconhecimento de que "o objeto das ciências humanas é o ser expressivo e falante" (Bakhtin, 2003, p.395), ou seja, ao utilizarmos a perspectiva histórico-cultural na pesquisa em ciências humanas, é necessário que a consideremos "como uma relação entre sujeitos possibilitada pela linguagem" (Freitas, 2003, p.29).

O que se buscou na pesquisa foi construir um ambiente de troca, surpresa, aprendizagem e descoberta para que as crianças se sentissem à vontade para expressar suas ideias, vontades, desejos, dúvidas, inquietações, descontentamentos, curiosidades e suas concepções, entendimentos e visões sobre os museus visitados e seus objetos.

A expressão das crianças foi visualizada a partir de disparadores de discursos bem definidos: suas vozes no ato da visita, suas fotografias e as cartas escritas no pós-visita. Ao valorizar e destacar as vozes das crianças, corroboramos nossa perspectiva central, qual seja, a de trazer o sujeito do acontecimento, a criança, para o centro da cena e da interpretação na pesquisa, enxergando-a como principal protagonista. Já por meio das fotos, tiradas pelas crianças durante as visitas 
aos museus, foi possível analisar o olhar, os enquadramentos e as seleções que foram feitos por elas. As cartas, produzidas após a visita aos museus, mostraram os elementos, objetos e situações selecionados para rememoração. Ou seja, nesses textos encontramos o que chamou a atenção das crianças, o que as marcou e impressionou de alguma forma a ponto de serem elementos "dignos" de serem comunicados para alguém querido e amado.

Assim, buscou-se, durante as visitas aos museus, compreender que mediações se projetam no processo de construção de uma relação da criança visitante com os museus. Nesse sentido, como podemos sintetizar a experiência realizada, e, consequentemente, responder nossa grande pergunta investigativa: como se dá a relação do sujeito visitante com o museu e com os objetos musealizados? Sinteticamente podemos dizer que tal relação se estabelece porque: 1) visitar museus ativa experiências coletivas, grupais e que, pela força de sua singularidade no interior do processo de socialização dos jovens, criam fortes elos de afeto que funcionam como mediadores dos sentidos atribuídos pela criança ao momento da visita; 2) há representações socialmente compartilhadas em relação ao entendimento do que é um museu que agem como filtros para o pensamento; 3) a criança sempre busca dar soluções ao que lhe parece inexplicável e, nesse sentido, capturar os sentidos atribuídos por ela ao espaço museal significa, tanto para professores como para educadores de museus, compreender melhor seu pensamento de modo a produzir soluções didáticas capazes de dialogar com os sujeitos cognitivos; 4) a dimensão material dos objetos museais dispara uma ação provocadora de sentidos no tocante às operações com a temporalidade histórica. Nesse sentido, museus são instituições parceiras diferenciadas e com grande potencialidade no sentido de favorecer, em crianças e jovens, a compreensão do Tempo; 5) Crianças afetadas pelo espaço museal, especialmente quando isso é provocado pelo trabalho pedagógico constituído a partir da visita, valorizam-no e o reconhecem como espaço de criação estética e, consequentemente, de aprendizagem.

Passemos a olhar mais pormenorizadamente cada um desses cinco eixos selecionados:

Dimensionando a força da narração das crianças em relação à ação da pesquisa salta-nos aos olhos o fato de que, acima de tudo, museus permitem instituir, graças à experiência extracurricular, uma prática social que, por ser realizada em grupo, é prenhe de sentidos permeados pela dimensão do afeto. 
O primeiro aspecto que se revelou com força quando possibilitamos às crianças a experiência com o museu é aquele que advém da possibilidade de permitir trânsitos compartilhados pela cidade, que se convertem em acontecimentos afetivos para o grupo.

É interessante ressaltar que a Escola Municipal José Calil Ahouagi fica afastada do centro da cidade de Juiz de fora e grande parte de seus alunos mora em bairros próximos à escola, ou seja, são crianças que, em sua maioria, usam e exploram pouco o centro da cidade e seus espaços públicos. Mas esse cenário não se distingue substantivamente daqueles casos e escolas situados em faixas sociais de alta renda e que apresentam condições mais favoráveis diante de uma exploração pedagógica dos museus.

Os museus visitados encontram-se localizados no centro de Juiz de Fora. São espaços públicos, mas pouco explorados não só por moradores de bairros distantes, na cidade, mas também pelas escolas tanto públicas quanto privadas que se situam no centro urbano. Em seu aspecto respeitável, enquanto alguns dos principais espaços de cultura da cidade, esses espaços ainda são muito pouco explorados no que tange às suas possibilidades de produção de conhecimento, de diálogo geracional e de intensificação de laços de sociabilidade.

Para as crianças participantes da pesquisa, os museus eram, até então, espaços distantes e idealizados. Boa parte delas nunca havia ido a um museu antes. Com a possibilidade de acesso à cultura e à cidade, proporcionada pelas visitas, uma nova experiência se formou e foi compartilhada por todo o grupo.

Nesse sentido, as visitas se tornaram singulares, marcantes e inesquecíveis, especialmente pelo fato de as crianças estarem juntas, com seus amigos, compartilhando um momento peculiar com pessoas especiais. A sociabilidade apareceu como um elemento importante nas visitas. $\mathrm{O}$ ato de compartilhar um momento singular converteu as visitas em algo que se desvia de uma experiência apenas individual, mas agora coletiva. É o que vemos, por exemplo, em uma das muitas cartas que circularam na escola, por meio de uma atividade de correio literário, onde Victória narra, à sua amiga Ialana, o prazer de estar junto na experiência de conhecer a cidade:

\section{Querida amiga Ialana,}

Ialana a visita no Museu Ferroviário foi muito legal porque eu e você tiramos muitas fotos. Eu gostei muito da Maria Fumaça, porque as 
meninas entraram nela, mas para sair os meninos pegaram as meninas. A parte que eu mais gostei foi a parte que eu gravei para você na hora que o trem passou. Depois fomos para o ônibus, falamos do museu. Eu falei que eu gostei muito foi do trem e dos sinos porque tem grandes e pequenos. Foi muito legal o nosso passeio, porque todos nós estávamos juntos nos divertimos muito. Beijos da Victória

Assim, o descobrir, explorar e se aventurar nos museus tornou-se uma experiência significativa, na vida das crianças, devido ao fato de elas estarem juntas com seus amigos, pessoas especiais, e também pelo encontro com espaços que emocionam, tocam e impactam as crianças. Trabalhamos aqui com a esperança de que na medida em que as escolas se deem conta dessa perspectiva, possam explorar visitas com menos pressa, maior intencionalidade didática quanto ao conjunto de eventos que pauta a visita e ao que o movimento de explorar a cidade em meio à experiência coletiva possa representar em termos de significância da atividade em si, independentemente das amarras impostas pela obrigatoriedade de cumprir dados conteúdos. O que queremos reforçar com isso é a ideia de que ir ao museu com as crianças não significa perder tempo, tampouco fazer atividades desprovidas de um sentido intrinsecamente vinculado aos conteúdos curriculares, mas promover uma prática educativa de direito de acesso à cidade que pode nos abrir, diante de nosso horizonte didático, inúmeras possibilidades de trabalho que, tal como os conteúdos do programa, formam, informam, qualificam o pensamento e a sensibilidade diante do mundo.

Crianças vão a museus - e ali filtram algumas de suas posições e opiniões - influenciadas pela presença mediadora de representações socialmente compartilhadas em relação ao entendimento do que é um museu.

As crianças não vão ao museu como se fossem uma tábula rasa, mas com alguns de seus olhares predeterminados por aquilo que já ouviram falar a respeito de museus. Assim, elas se deslocam pelos espaços tentando reforçar, para si e para o grupo, ideias que favorecem, em boa parte dos casos, a representação de museu como um espaço que abriga objetos antigos.

Vejamos cenários e exemplos que nos auxiliam a perceber tal dimensão: 
Professora: O que vocês acham que vão encontrar lá, o que vocês imaginam que vão ver lá no MAMM?

Ialana: Ah ... várias coisas velhas, ah .... velhas, não! Coisas antigas.

Nayuri: Tia, o museu tem osso de dinossauro lá?

Professora: Você acha que vai encontrar osso de dinossauro lá?

Nayuri: Eu acho.

Luana Almeida: Muitos quadros e osso de dinossauro.

Yasmim: Eu imagino que seja um lugar com artes, quadros, esculturas e coisas antigas e velhas. Quem sabe até uma múmia.

Conversas como essa foram recorrentes entre a maior parte das crianças que evidenciaram ter, tanto para com o Museu de Arte Contemporânea quanto para o Museu Ferroviário, a perspectiva de que museu é lugar de coisas velhas, o que as levou até mesmo a uma atitude de desconfiança em relação ao Museu da Arte, na medida em que, ao não trazer em seu acervo coisas "velhas", ele não deveria ser um museu.

Em um momento da visita no Museu Ferroviário, no espaço da bilheteria da estação, seguiu-se o seguinte diálogo entre uma menina e a professora Yara Cristina Alvim, pesquisadora vinculada ao grupo Cronos, que atuou como observadora participante voluntária, auxiliando na coleta de dados processada nos momentos de visita:

Menina: A gente não pode entrar nesse lugar.

Yara: Por que será que não pode entrar aí?

Menina: Porque é muito antigo e tem coisa muito rara. Se perder uma peça não consegue mais encontrar.

Percebe-se que a criança relacionou o espaço museal a um ambiente de antiguidades e raridades, evidenciando, mais uma vez, a visão e a ideia de museu que povoa seu imaginário. Mas também é possível diagnosticar, nessa fala, uma determinada consciência de preservação dos objetos. Como podemos ver, a ideia de museu que essas crianças carregam em seu imaginário está diretamente relacionada com o passado, com seus objetos antigos e vestígios de um tempo pretérito. 
Talvez daí tenha surgido certo estranhamento em relação ao MAMM e seus objetos. Na conversa com Yasmim e outras crianças na ida ao MAMM, Yasmim havia dito que esperava encontrar objetos velhos e antigos. Contudo, não foi isso que ela viu. Essa aluna e as outras crianças encontraram esculturas cerâmicas e quadros que mais se relacionavam com o presente do que com o passado, na visão delas. Dessa forma, o MAMM não se enquadra na visão delas do que é um museu, e, por isso mesmo, dispara outras experiências. O Museu Ferroviário reitera uma dada visão e expectativa de museu, que o MAMM corrompe.

É notório o encantamento que o acesso a objetos do passado despertou nessas crianças: a ideia de voltar ao passado para usar alguns objetos e andar de trem é, para elas, algo encantador e, portanto, o passado seduz também por seu potencial imaginativo, tantas vezes descartado em práticas escolares. Acreditamos também que a própria disposição dos objetos no Museu Ferroviário, as salas e a arquitetura do prédio contribuíram, de alguma forma, para tal impressão e desejo. Nesse sentido, o fascínio despertado pelo Museu Ferroviário encontra-se no fato de ele corroborar a visão de museu que as crianças têm, além de que o apelo histórico torna-se muito maior pelo fato de aquele lugar ter sido, efetivamente, palco de muitas histórias e acontecimentos no que tange à história da ferrovia.

Crianças no interior de museus, em contextos de mediação grupal, buscam um pensamento lógico e uma atitude interpretativa do próprio espaço museal.

Todas as experiências de visita realizadas ao longo da pesquisa nos evidenciaram o quanto ocorre a busca constante, por parte das crianças, de interpretar, ler e compreender tudo o que viam. Para isso, elas elaboraram lógicas que buscam explicar aquilo que não lhes é compreensível à primeira vista. Assim, quando havia, próximos aos objetos, textos e legendas, foram utilizados como suporte para compreensão e leitura dos objetos e do espaço museal. Porém, quando não havia, elas acionavam outros recursos para atingir tal fim: buscavam interpretar os objetos expostos a partir daquilo que elas conheciam ou fazia sentido para elas. 
Assim, foi possível diagnosticar que as crianças, ao depararem com a exposição e com os objetos expostos, criaram uma rede de sentidos e significados para aquilo que elas estavam vendo/sentindo/experimentando/vivenciando. Os sentidos atribuídos aos objetos e aos espaços museais foram individuais, na medida em que refletiram e refrataram o contexto em que cada criança estava inserida.

Nesse sentido, ao compreendermos o discurso museológico como um enunciado, isto é, "unidade da comunicação discursiva" (Bakhtin, 2003, p.276), devemos levar em conta que "todo enunciado constitui-se a partir de outro enunciado, é uma réplica a outro enunciado" (Fiorin, 2006, p.24). Assim, na medida em que um enunciado solicita uma resposta podemos pensar no variado número de enunciados criados dentro de um museu. Dessa forma, as crianças, ao depararem com o discurso museológico, elaboram também os seus enunciados, ou seja, uma compreensão ativa e responsiva daquilo que elas estavam vendo. De acordo com Bakhtin (2003),

Neste caso, o ouvinte, ao perceber e compreender o significado (linguístico) do discurso, ocupa simultaneamente em relação a ele uma posição ativa e responsiva: concorda ou discorda dele (total ou parcialmente), completa-o, aplica-o, prepara-se para usá-lo, etc.; essa posição responsiva do ouvinte se forma ao longo de todo o processo de audição e compreensão desde o seu início, às vezes literalmente a partir da primeira palavra do falante. Toda compreensão da fala viva, do enunciado vivo é de natureza ativamente responsiva (embora o grau desse ativismo seja bastante diverso); toda compreensão é prenhe de resposta, e nessa ou naquela forma a gera obrigatoriamente: o ouvinte se torna falante. (p.271)

Ao depararem com o discurso museológico (museografia e suas intencionalidades) as crianças em geral não permaneceram imóveis ou indiferentes, ainda que por vezes lhes seja exigida uma atitude de silêncio e atenção com o que é explicável pelos guias e/ou educadores de museus. Dessa forma, o olhar atento da criança a cada minúcia presente nos museus apareceu como algo marcante. Elas tentaram, a todo momento, depreender sentidos, não necessariamente convergentes com os pressupostos de cada curadoria, mas de acordo com aquilo que, para elas, faz sentido.

Pensemos alguns cenários e exemplos que referendam tal evidência. 
Sem que ninguém lhes propusesse tal atividade, quase todas as crianças contaram as imagens presentes no mural "300 santos" para verificar se, de fato, existiam 300 esculturas. Logo, chegaram à conclusão de que não existiam. Como outra solução para essa questão, elas rapidamente contaram todas as imagens da exposição para verificar se o número proposto no mural era "correto". Nesse momento, chegaram à conclusão que só existiam 121 imagens na exposição. Todas as crianças fizeram esse mesmo movimento - o que fortalece a dimensão da mediação coletiva e grupal disparada no processo de uma visita - e ficaram intrigadas com o fato. Ou seja, elas possuem um movimento de buscar o entendimento de um processo de categorização. Interpretar um nome é decodificar uma categorização atribuída, buscando significados.
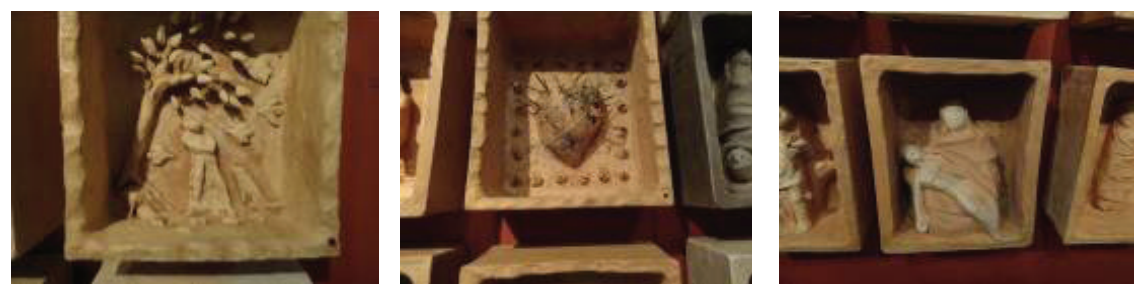

Figura 1 - Algumas imagens selecionadas pelas crianças no mural "300 santos" Fonte: acervo das crianças

É interessante perceber a postura das crianças na leitura das fontes, ou seja, dos objetos e do próprio espaço museal, e como a sua leitura é acompanhada de indagações, busca de respostas, construção de lógicas explicativas e hipóteses.

Tal fato também aparece nas cartas trocadas no âmbito da atividade realizada em sala de aula, como, por exemplo, na de Yasmin, na qual ela afirma que "Depois voltamos para baixo e vimos os '300 santos', não tinha 300 santos, esse era o nome da obra do Hélio Siqueira”.

Como podemos ver, há uma construção conceitual, pautada na interpretação do título da obra. Assim, a lógica construída pela aluna gira em torno da constatação da não existência de 300 esculturas de cerâmica; logo, esse é apenas o nome da obra. A interpretação relaciona-se com a criação de uma dada consciência conceitual.

Durante a exploração livre do espaço museal, nenhuma das crianças se deteve a analisar o texto de abertura da exposição e o título. Com isso, elas não 
sabiam quem havia confeccionado aqueles objetos e, assim, surgiram ideias como a de Victória. Segundo ela, muitas pessoas haviam feito aqueles objetos, já que se tratava de um grande número. As peças que estavam na vitrine também despertaram a atenção da menina. De acordo com a aluna, as peças que estavam lá era porque estavam "frescas", ou seja, haviam sido confeccionadas pouco tempo antes.

Depois de alguns minutos, Victória, que ainda continuava querendo entender o porquê de algumas peças estarem na vitrine, chegou à conclusão de que elas estavam lá porque já haviam sido vendidas. Tal lógica foi disparada a partir do momento em que o monitor argumentou que todas as peças que estavam com o adesivo preto já haviam sido vendidas. Mas apenas algumas imagens que estavam dentro das vitrines já haviam sido vendidas, ou seja, possuíam o adesivo preto.

O movimento dessa criança demonstra que ela esteve atenta à museografia ao tentar compreender por que algumas esculturas estavam dentro de vitrines e outras não; ou seja, ela buscou interpretar, ainda que a seu modo, a museografia, por meio de suas seleções e ordenamentos.

O seu impulso foi o de procurar compreender o arcabouço de significados existente no museu e em seus objetos que representam as escolhas, seleções e intenções dos dirigentes e também daqueles que pensaram, planejaram e arquitetaram a exposição (expografia e museografia).

O mesmo movimento aconteceu no Museu Ferroviário, quando as crianças depararam com a réplica em miniatura de uma Maria Fumaça, na sala "História da Ferrovia". Esse objeto chamou a atenção das crianças desde o início da visita. O que se destacou, em um primeiro momento, foi o fato de a miniatura da Maria Fumaça ser a única peça, naquela sala, que estava dentro de uma vitrine. Assim, em um movimento de buscar ler e interpretar a museografia daquele espaço, perguntaram para uma funcionária o porquê de aquele objeto estar lá. Quando elas ficaram sabendo que a miniatura demorou 18 anos para ficar pronta, todas ficaram espantadas e admiradas. É compreensível o porquê de tal reação: a dimensão temporal do que representam 18 anos, para essas crianças, é impressionante. Esse tempo parece ser infinitamente longo para elas, que viveram até agora pouco mais da metade do período necessário para confeccionar a peça. 


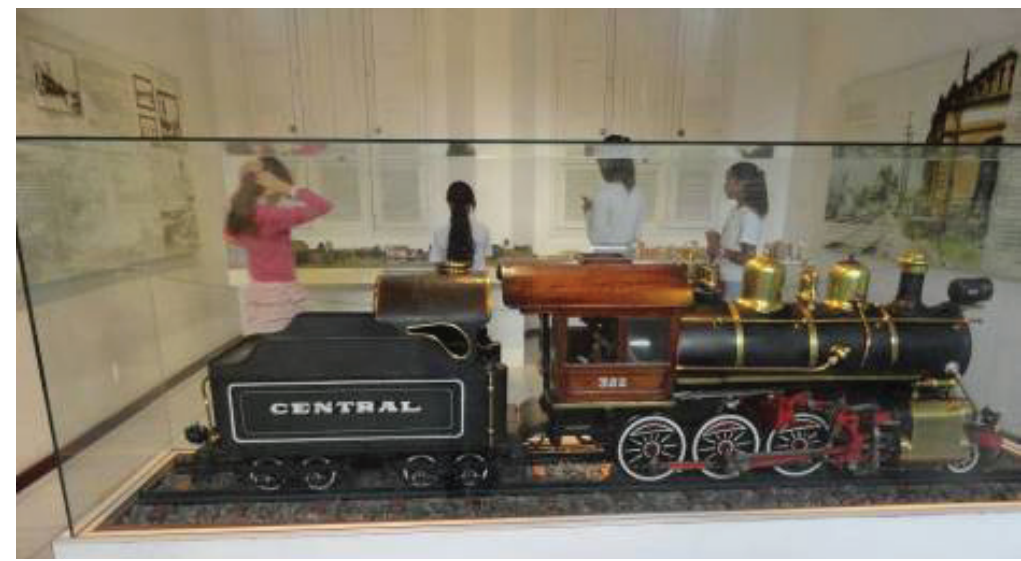

Figura 2 - Miniatura da Maria Fumaça

Fonte: acervo das crianças

\section{PELO ESFORÇO DE OPERAÇÃO COM A TEMPORALIDADE HISTÓRICA}

Francisco Regis Ramos (2004) dedicou-se, em sua obra seminal sobre a questão dos objetos em museus, a evidenciar em que medida os objetos museais, ao serem sacralizados por uma aura que os cerca em termos do espaço expositivo, ganham sentidos novos ao serem destituídos de seu valor de uso original. Uma cadeira exposta em um museu já não serve mais como cadeira, mas traveste-se de um novo sentido que, por sua vez, ao ser lido, será interpelado pelos componentes produtores de sentido e elementos de memória do sujeito visitante. Portanto, cada um qualificará uma cadeira antiga, por exemplo, tendo como referência seus próprios elementos significantes e sua própria experiência com diferentes cadeiras.

Se consideramos a abertura a leituras e olhares abertos pelo objeto posto na exposição em meio à polifonia engendrada pela experiência de leitura, veremos também que, em meio a essa polifonia, as crianças buscam dar soluções e explicações a esse estranho tempo chamado passado. O que a investigação realizada nos permitiu perceber e capturar é que as crianças diante dos objetos museais não ficam inertes e buscam conferir-lhes sentido no tocante a um sentido de orientação temporal.

Um exemplo interessante desse movimento pode ser observado a partir de um evento trivial ocorrido em uma das visitas. No Museu Ferroviário, havia, 
na sala Sinalização e Via Permanente, uma placa que dizia "É prohibido transitar pela linha - multa $5 \$ 000$ ". As crianças, ao verem essa placa, lançaram imediatamente uma série de perguntas e interpretações do que seria “ $5 \$ 000$ ". Algumas afirmaram que a placa devia estar errada, outras argumentaram que o valor especificado seria 5 reais, outra que a multa seria de 500 reais, e outra criança afirmou que seria de 5.000 reais. Durante o processo de explicação elas puderam compreender que, na verdade, $5 \$ 000$ significa 5.000 mil-réis, porém essa moeda foi utilizada, no Brasil, há várias décadas, um momento que nem essas crianças nem os seus pais viveram. Dessa forma, é válido notar o esforço e a busca pela compreensão do que veem, a constituição de uma lógica explicativa, sendo essa leitura sempre marcada pelo presente, isto é, pelo universo de significação conhecido da criança, conforme aquilo já pautado nas pesquisas de Sandra Oliveira (2003).

Outra situação parecida, quando o uso do presente na leitura do passado se fez marcante, foi quando as crianças depararam com a máquina de escrever e o telégrafo. Elas relacionaram tais objetos ao computador, como podemos diagnosticar na fala de Yago, ao explicar o funcionamento da máquina de escrever para mim: "Tia, você coloca o papel ali dentro e digita" (grifo nosso). E outras crianças argumentaram: "a diferença é que não tem tela".

Do mesmo modo, no Museu de Arte Murilo Mendes, o esforço de buscar uma orientação temporal, ainda que difuso diante de outros elementos trazidos

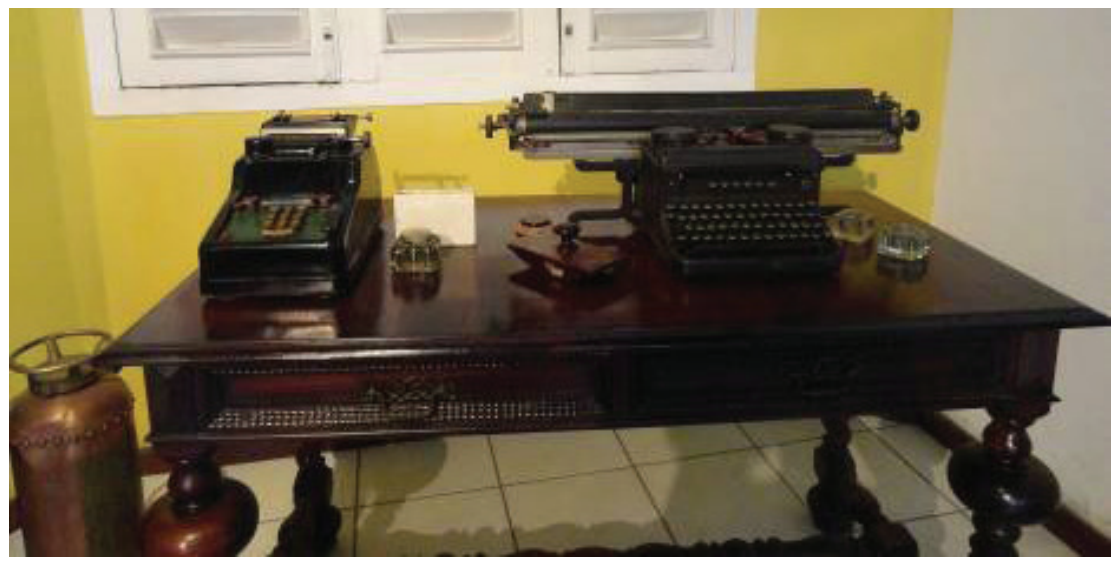

Figura 3 - Calculadora e máquina de escrever Fonte: acervo das crianças 
pela ênfase nas dimensões da criação estética, comparecia e evidenciava o movimento das crianças em buscar explicar aquilo que lhes parecia fora do tempo do agora. Cada criança se esforçava, à sua maneira, para compreender e interpretar os objetos da exposição "Santos todos nós", de Hélio Siqueira. Olhavam atentamente para cada objeto e para a sua respectiva legenda. Muitas delas faziam a leitura das legendas e as tomavam como informação e como suporte de investigação da obra. Uma situação exemplar é de Luana, que, junto a outros alunos, estava observando atentamente a legenda dos objetos. Ao nos aproximarmos foi possível perceber que eles estavam verificando a "idade" daquelas peças, subtraindo o ano que constava nas legendas de 2012. Esse movimento foi repetido em vários objetos por diversas crianças. O mesmo movimento aconteceu no Museu Ferroviário, porém somente com as peças que possuíam legendas que informavam as datas.

Cabe destacar, em especial, a fala de algumas crianças com Yara, que, conforme já apontamos anteriormente, acompanhou a visita na qualidade de pesquisadora observadora. Elas estavam olhando atentamente para o ambiente, quando uma perguntou a ela: "Tia, você sabe se eles limpam aqui? Yara perguntou: “O que vocês acham?”. A criança respondeu: "Eu acho que não, porque está com poeira e tem teia de aranha". Ela perguntou: "Por que vocês acham que eles não limpam?”. Outra criança interveio: “Eles não limpam para mostrar que é antigo".

É interessante notar a presença de duas questões importantes presentes nessa fala: primeiramente, a associação que elas fazem entre poeira e teia de aranha com antiguidade. De onde viria tal associação? Com base em que elementos elas fizeram essa inferência? Em segundo lugar, a percepção do que representa o espaço museal: o lugar onde se quer mostrar algo que é antigo. A resposta da aluna tem uma lógica explicativa, uma determinada consciência temporal (Oliveira, 2003), marcada pela causalidade, o que é visível na relação estabelecida, "poeira e teia de aranha - antiguidade - museu".

Museus são espaços que permitem a ativação de uma sensibilidade quanto às potências vinculadoras entre criação estética e aprendizagem.

Por fim, um último item que nos chamou a atenção foi o reconhecimento, por parte das crianças, dos museus como espaço de fruição estética, lugar de 
aprendizagem e descobertas. Ou seja, o museu como espaço para refletir sobre o conhecimento, por intermédio de suas linguagens.

Já que a materialidade do objeto dispara uma relação com aquilo que vai além da língua escrita, tal aspecto proporciona, também, uma relação múltipla com as linguagens que atravessam a museografia, com os elementos ligados à intencionalidade que está por trás da exposição. O museu lança essa relação, até mesmo inclusive com a convergência das diversas linguagens, para produzir uma determinada possibilidade de pensamento.

Assim, para as crianças, a função do museu de arte também se relaciona com a exploração desse lugar para a fruição, ou seja, com a ideia de conhecer pinturas e obras de arte, usufruir, descobrir e apreciar coisas novas. Pensemos um cenário que nos permite dimensionar tal evidência.

- Para que serve um museu de arte?

Maysa: Para marcar na história a pintura.

Laura: Para a gente ver um quadro que a gente nunca viu.

Willians: Para ver variedades de artes. Pinturas, quadros e esculturas.

Rafaela: Para mostrar às pessoas o que é arte e para valorizar mais.

Quételei: Para a gente conhecer a arte brasileira e estrangeira.

Victória: Eu acho que eles fizeram a pintura não foi só para eles guardarem para eles, eu acho que eles fizeram para todo mundo ver.

Nayuri: Eu acho que eles pintaram para a gente achar que é bonito as esculturas dos artistas.

- O que vocês esperam hoje da visita ao Museu Ferroviário?

Lidiane: Uns objetos de ferro, sei lá. Eu espero que seja boa, legal. Que eu vou aprender algumas coisas.

Tipo o quê?

Quételei: Aprender mais sobre o trem, ferro, essas coisas. Eu acho que é sobre isso que é o museu.

Como podemos ver, essas crianças relacionaram, de forma indireta e direta, em alguns casos, o museu com aprendizagem, ou seja, com o conhecer o novo. Assim, os museus não são apenas espaços de fruição estética e de aprendizagem, há que se reconhecer o importante papel do "museu como espaço do 
encontro e de debate, onde a dimensão criativa e produtiva pode ser incorporada, substituindo a dimensão reprodutiva, na qual apenas o que já foi produzido e legitimado é comunicado" (Moura, 2005, p.28).

Nesse sentido, o museu se apresenta, claramente, como um espaço de aprendizagem, porém, nesse caso, mediada pelos objetos. A visita ao museu, para elas, se relacionou com o conhecer o novo, aprender coisas novas e experimentar experiências únicas com o grupo de amigos, como um espaço aberto à contemplação do belo, e que permite e favorece a sensibilidade. Assim, o que temos nessas falas são respostas concretas dos processos cognitivos e culturais, além dos movimentos de ressonância cultural, que são despertados pelos museus quando as crianças ganham uma oportunidade, como essa, de conhecer dois museus bastante distintos que, acima de tudo, permitem novos acessos à cidade onde vivem.

Cabe-nos esclarecer, à guisa de encerramento, que a relação museu-escola não seria, no início, um ponto central nesta pesquisa. É preciso ressaltar que esse foi um espaço construído pela escola dentro desta pesquisa. Ao contrário do que ocorre, na maioria dos casos, com as relações de desencontro ou de encontros meramente formais da escola com o museu, o que vivenciamos foi algo bastante distinto.

A dimensão educativa que tanto buscava, desde o início da pesquisa, e que havia encontrado, de forma muito tímida, dentro dos museus - até mesmo porque museus são espaços potencialmente educativos, mas não possuem uma natureza ontológica educativa -, foi encontrado, com toda força, no trabalho desenvolvido pela escola após as visitas. Aí sim as visitas se tornaram educativas: graças ao trabalho pedagógico e o investimento realizado pela escola, em especial pela professora regente Lourdes. ${ }^{4}$ Tal trabalho, todavia, não faz parte do escopo e da intencionalidade deste artigo, ainda que possa ser recuperado no interior da dissertação que lhe confere substrato.

Assim, o que propomos como um novo caminho a ser trilhado numa educação voltada para a valorização do patrimônio seria buscar pesquisar ações e propostas que conversem com os processos de significação executados pelos sujeitos. Afinal de contas, como nos foi possível perceber nesta pesquisa, eles buscam, a todo momento, significar e interpretar os objetos e tudo o que está à sua volta a partir de seus filtros e referenciais de leitura, possibilitando múltiplas formas de expressão e, acima de tudo, a possibilidade de encontrar uma 
cidade que muitas vezes lhes é interditada ou desconhecida. Por que não dimensioná-los com mais força em nossas possibilidades de trabalho escolar?

\section{REFERÊNCIAS}

ALMEIDA, Nervenson Paulo de. O Museu de Arte Moderna Murilo Mendes, hoje, pode ser considerado um atrativo turístico? (Monografia). Faculdade de Turismo de Juiz de Fora. Juiz de Fora, MG, 2007.

ABREU, Regina; CHAGAS, Mário (Org.) Memória e patrimônio: ensaios contemporâneos. 2.ed. Rio de Janeiro: Lamparina, 2009.

ABREU, Regina. A emergência do patrimônio genético e a nova configuração do campo do patrimônio. In: ABREU, Regina; CHAGAS, Mário (Org.) Memória e patrimônio: ensaios contemporâneos. 2.ed. Rio de Janeiro: Lamparina, 2009. p.3448.

BAKHTIN, Mikhail. Os gêneros do discurso. In: Estética da criação verbal. Trad. Maria Ermantina Galvão Gomes Pereira. São Paulo: Martins Fontes, 1992. . Estética e criação verbal. São Paulo: Martins Fontes, 2003. . O freudismo. Trad. Paulo Bezerra. São Paulo: Martins Fontes, 2004.

BAKHTIN, Mikhail (VOLOCHINOV). Marxismo e a filosofia da linguagem. 4.ed. São Paulo: Hucitec, 2009.

BALERDI, Ignacio Diaz. La memoria fragmentada: el museo y sus paradojas. Santiago de Compostela: TREA, 2008.

BOGDAN, R.; BIKLEN, S. Investigação qualitativa em educação: uma introdução à teoria e aos métodos. Porto: Porto Ed., 1994.

CHAGAS, Mario. A imaginação museal: museu, memória e poder em Gustavo Barroso, Gilberto Freyre e Darcy Ribeiro. Rio de Janeiro: Ibram, 2009.

ERVEN, Maria Fernanda van. Crianças no templo das musas: mediadores culturais e aprendizagens em museus. Dissertação (Mestrado) - Programa de Pós-Graduação em Educação, Universidade Federal de Juiz de Fora (UFJF). Juiz de Fora, MG, 2013.

FIORIN, José Luiz. Introdução ao pensamento de Bakhtin. São Paulo: Ática, 2006.

FREITAS, Maria Teresa. Bakhtin: Bakhtin e a psicologia. In: Vygotsky e Bakhtin: psicologia e educação, um intertexto. São Paulo: Ática, 2003. p.125-131.

HUYSSEN, Andreas. Seduzidos pela memória. Rio de Janeiro: Aeroplano, 2000.

MIRANDA, Sonia Regina. Estranhos passados encontrados em um museu: a criança 
e seus olhares sobre o tempo desconhecido. Caderno CEDES 82 - Educar para a compreensão do tempo, Campinas, SP, v.30, n.82, p.369-382, set.-dez. 2010.

MOURA, Maria Teresa Jaguaribe A. de. Arte e infância: um estudo das interações entre crianças, adultos e obras de arte em museus. Dissertação (Mestrado) - PUC-RJ. Rio de Janeiro, 2005.

NORA, Pierre. Entre memórias e história: a problemática dos lugares. Projeto História, São Paulo: PUC-SP, n.10, p.7-28, 1993.

OLIVEIRA, Sandra Regina Ferreira. O tempo, a criança e o ensino de História. In: ROSSI, Vera Lúcia Sabongi; ZAMBONI, Ernesta. Quanto tempo o tempo tem! Campinas, SP: Alínea, 2003.

PEREIRA, Júnia Sales; CARVALHO, Marcus Vinícius Corrêa. Sentidos dos tempos na relação museu/escola. Caderno CEDES 82 - Educar para a compreensão do tempo, Campinas, SP, v.30, n.82, p.383-396, set.-dez. 2010.

RAMOS, Francisco Régis Lopes. A danação do objeto: o museu no ensino de história. Chapecó, RS: Argos, 2004.

SANTOS, Myrian Sepúlveda dos. Museu Imperial: a construção do Império pela República. In: ABREU, Regina; CHAGAS, Mário (Org.) Memória e patrimônio: ensaios contemporâneos. 2.ed. Rio de Janeiro: Lamparina, 2009. p.115-135.

SIQUEIRA, Hélio. Hélio Siqueira: depoimento. Fernando Pedro da Silva e Marília Andrés Ribeiro (Coord.) Belo Horizonte: C/Arte, 2000.

VYGOTSKY, Lev Semyonovich. A construção do pensamento e da linguagem. São Paulo: Martins Fontes, 2001.

Psicologia da arte. São Paulo: Martins Fontes, 2001.

A formação social da mente. São Paulo: Martins Fontes, 1991.

\section{NOTAS}

${ }^{1} \mathrm{Na}$ verdade Juiz de Fora possui um importante Museu Histórico, portador de grande densidade histórica e forte componente na memória coletiva da cidade, presente no circuito dos principais museus do país. Trata-se do Museu Mariano Procópio, que todavia encontra-se fechado já há alguns anos para o público em geral, dispondo somente de seu parque aberto à visitação. Por essa razão, optou-se naquela pesquisa por trabalhar com as crianças junto a outra instituição que apresentasse essa tipologia "histórica", ainda que possa ser questionada como modo de categorização, especialmente se considerarmos que todo museu é histórico, artístico e científico.

${ }^{2}$ Disponível em: www.ufjf.br/mamm/2013/02/03/\%E2\%80\%9Cpinturas-na-colecao-murilomendes\%E2\%80\%9D-e-prorrogada-ate-o-mes-de-marco; Acesso em: 7 mar. 2013. 
${ }^{3}$ Disponível em: www.ufjf.br/mamm/2013/02/03/\%E2\%80\%9Cpinturas-na-colecao-murilo-mendes\%E2\%80\%9D-e-prorrogada-ate-o-mes-de-marco/; Acesso em: 7 mar. 2013.

${ }^{4}$ Agradecemos a Lourdes de Fátima Cruz Reis, professora regente de História da Escola José Calil Ahouagi, que participou de todas as etapas do campo. Sua contribuição e participação foram essenciais para o desenvolvimento da pesquisa.

Artigo recebido em 24 de setembro de 2014. Aprovado em 23 de outubro de 2014. 